\title{
The Ansa Cervicalis in Fetuses
}

\author{
El Asa Cervical en Fetos
}

\author{
P. Pillay; P. Partab; L. Lazarus \& K. S. Satyapal
}

PILLAY, P.; PARTAB, P.; LAZARUS, L. \& SATYAPAL, K. S. The ansa cervicalis in fetuses. Int. J. Morphol., 30(4):1321-1326, 2012.

SUMMARY: The formation of ansa cervicalis (AC) is somewhat complex with both its course and location along the common carotid artery and internal jugular vein (IJV) varying. The aim of the study was to document the anatomy, formation and variations of AC. Forty fetuses (gestational age: 15 to 28 weeks) were obtained from the Department of Clinical Anatomy, Westville Campus, UKZN. A detailed micro-dissection of the posterior triangle of the neck and $\mathrm{AC}$ were completed using standard micro-dissecting instruments. Results of the formation of AC, its relationship to IJV and variations were recorded. The superior root was identified as a long willowy nerve that branched from the hypoglossal nerve, descended on the carotid sheath, anterior to the common carotid artery and IJV in $70 \%$ and posterior to IJV in $30 \%$ of the specimens. The inferior root of AC originated from the ventral rami of C2-C3 in 26\%; ventral ramus of $\mathrm{C} 3$ in 58\% and ventral ramus of $\mathrm{C} 2$ in 16\%. Variations: a) Formation: (i) Dual formation of AC: The Hypoglossal nerve formed separate loops with the ventral rami of $\mathrm{C} 2$ and $\mathrm{C} 3$ (3\%); (ii) "W" shaped appearance of AC above the superior belly of omohyoid (1\%); (iii) A "vago-cervical complex" 3\%; b) Origin and course: The superior root of AC received a contribution from the hypoglossal nerve, a short distance later it formed a loop around the IJV to ascend to the ventral ramus of C2 as the inferior root. The precise understanding of the anatomy of AC together with variations may assist anesthetists and surgeons to accurately identify the vascular and neural relations during surgical procedures.

KEY WORDS: Ansa cervicalis; Superior root; Inferior root; Hypoglossal nerve; Internal jugular vein.

\section{INTRODUCTION}

Classically, the ansa cervicalis (AC) has been defined as a simple yet complicated loop, which has superior and inferior roots that join anterior to the carotid sheath (Chhetri $\&$ Berke, 1997). It has been previously established that the original latin term "ansa" (meaning "handle of cup or shaft") was initially used to describe the looped portion of the AC; however recent literature has defined it as encompassing both the superior and inferior roots (Banneheka, 2008).

The superior root of the AC has been described as a long slender branch that leaves the hypoglossal nerve (as it curves around the occipital artery) to descend on the anterior wall of the carotid sheath, lateral to the internal jugular vein (IJV). At its origin, the superior root lies medial to the posterior belly of the digastric muscle and lateral to the internal and external carotid arteries (Kuniak \& Klacansky, 1982). The superior root then crosses the IJV at the midline of the neck continuing forward to join the inferior root of AC, anterior to the carotid artery (Vollala et al., 2005; Standring \& Henry, 2008). This inosculation between the hypoglossal nerve and cervical plexus has been described by various anatomists over the years as either the $\mathrm{AC}$ or ansa hypoglossi (Ellis \& Fieldman, 1993; Banneheka; Standring \& Henry). The superior and inferior roots descended on the anterior surface of carotid sheath forming a loop that gave off branches to the infrahyoid neck muscles (Fig. 1). According to the classification as 'long' or 'short' roots by Loukas et al. (2007), he described location of "the union between the two roots" as inferior to the superior belly of omohyoid muscle and superior to the muscle, respectively.

Standard anatomical texts describe the inferior root arising from the ventral rami of the second and third cervical nerves (Standring \& Henry). Poiviraev \& Chernikov (1967) suggested that the ventral rami of the first and fourth cervical nerves may contribute to the formation of the inferior root. In addition, in the study conducted by Caliot \& Dumont (1983), the ventral ramus of the third cervical nerve was the most frequent contributor to the inferior root and was later corroborated in 2007 by Loukas et al. However, Olry \& Haines (2002) reported the formation of the inferior root by the ventral rami of the first and second cervical nerves only. 


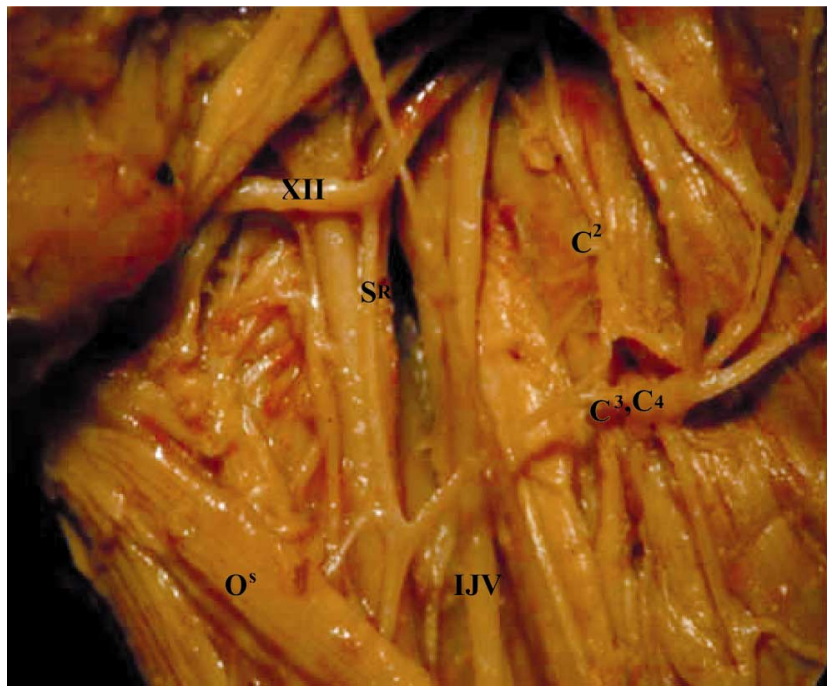

Fig. 1. Left anterior view of origin of AC and the innervation of the superior belly of omohyoid muscle.

Key= XII: Hypoglossal nerve; SR: Superior root of ansa cervicalis; IJV: Internal jugular vein; Os: Superior belly of omohyoid muscle; $\mathrm{C} 2$ : ventral rami of the second cervical nerve; $\mathrm{C} 3, \mathrm{C} 4$ : ventral rami of the third and fourth cervical nerves.

There have been reports of the complexity of the formation of the $\mathrm{AC}$ and its varying course along the common carotid artery and IJV (Chhetri \& Berke, 1997).

Yamada \& Mannen (1965) classified the relationship of the AC to the IJV as either belonging to lateral or medial categories. The lateral and medial patterns described the AC as being located either posterior or anterior to the IJV, respectively. Standring \& Henry further corroborated this description by reporting an anterior relationship of the $\mathrm{AC}$ to the IJV. However, it was also reported by Kikuchi (1970) that the AC could also be located medical to the IJV. Furthermore, Banneheka described a mixed type arrangement of $\mathrm{AC}$ to the IJV: this occurs when the inferior root has two or more branches that join the superior root and at least one of these branches cross the vein laterally and the other crosses medially. In the literature reviewed, anatomy and variations of adults are well documented, however studies involving fetal anatomy and variations were not recorded

Due to the close proximity of AC to the larynx, this nerve is often used during laryngeal reinnervation surgery for nerve to nerve transfer to the recurrent laryngeal nerve in children, adolescents, young adults and adults. Therefore, the aim of the study was to document the anatomy of the ansa cervicalis in fetuses and the variations encountered.

\section{MATERIAL AND METHOD}

Forty fetuses (gestational age: 15 to 28 weeks) (right side: 40/80; left: 40/80) were obtained from the Department of Clinical Anatomy, University of KwaZulu-Natal in accordance with the National Health Act 61 of 2003 and Human Tissue Act 65 of 1983: Ethical Clearance No: BF 156/07. Fetal cadaveric specimens with signs of injuries, trauma or pathology in the lateral and posterior compartments of the neck were excluded. The dissection of the posterior triangle of the neck and the detailed dissection of the AC were completed using the standard microdissecting instruments (Carl Ziess Stemi DV4) and the results of the formation of the AC, its relationship to the IJV and variations were recorded and photographed using a Canon digital camera.

\section{RESULTS}

Origin of AC. The superior root arose from the hypoglossal nerve as a long willowy nerve, and descended on the carotid sheath either anterior $(56 / 80(70 \%))$ (Fig. 2) or posterior $(24 / 80(30 \%))$ to the common carotid artery and IJV (Fig. 3). In 1965, Yamada classified this pattern into medial and lateral series (Yamada \& Mannen). The inferior root of the $\mathrm{AC}$ was formed from the ventral rami of C2 and C3 (21/80 (26\%)), ventral ramus of C3 (46/80 (58\%)) (Fig. 4) and ventral ramus of C2 (13/80(16\%)) (Fig. 5).

Formation and course of AC. In the current study, the majority of specimens $(63 / 80,(79 \%))$ depicted the pattern of a short AC whereby the loop was located superior to the superior belly of omohyoid muscle (Fig. 6 - indicated by arrow). In addition, 2-3 branches came off directly from the summit of the loop to innervate the superior belly of omohyoid and sternothyroid muscles.

\section{Variations.}

i) Dual AC formation: The first loop was formed by the superior root receiving the normal contribution from the hypoglossal nerve and the inferior root was formed by the ventral ramus of $\mathrm{C} 2$. The second loop was formed by the continuation of the superior root and the ventral ramus of C3. This usual dual formation of AC was observed in 2/80 (3\%) of the fetal specimens (Fig. 7 -indicated by dotted square).

ii) The superior root of the $\mathrm{AC}$ received a contribution from the hypoglossal nerve, then a short distance later it formed 


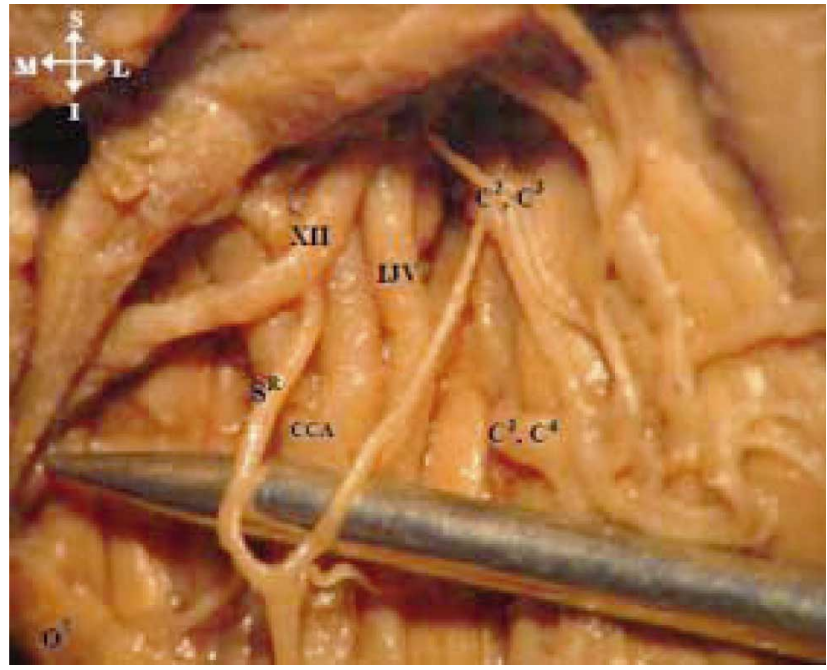

Fig. 2. Right anterior view of the AC located anterior to IJV \& CCA.

Key= XII: Hypoglossal nerve; SR: Superior root of ansa cervicalis; IJV: Internal jugular vein; Os: Superior belly of omohyoid muscle; C2, C3: ventral rami of the second and third cervical nerves; $\mathrm{C} 3, \mathrm{C} 4$ : ventral rami of the third and fourth cervical nerves; CCA: Common carotid artery.

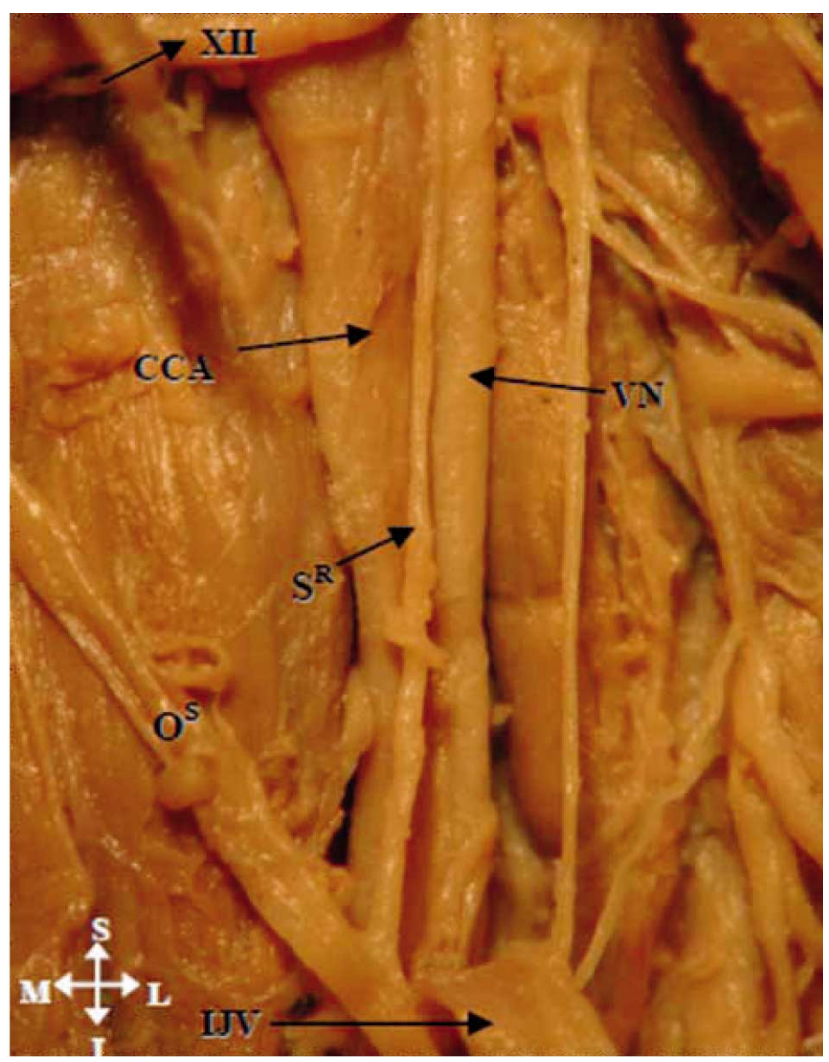

Fig. 3. Right anterior view of superior root of AC located posterior to internal jugular vein. The internal jugular vein has been reflected anteriorly to depict the AC.

Key= XII: Hypoglossal nerve; SR: Superior root of AC; CCA: Common carotid artery; VN: Vagus nerve; Os: Superior belly of omohyoid muscle; IJV: Internal jugular vein.

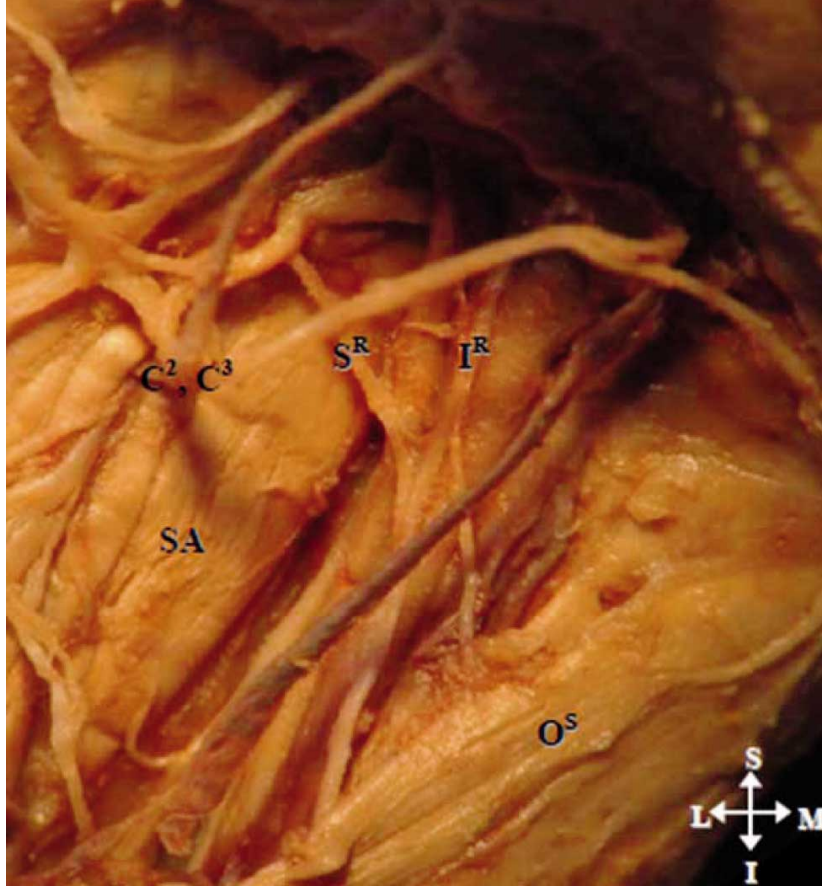

Fig. 4. Right anterior view of origin of inferior root from ventral rami of second cervical nerves (indicated by arrow)

Key= SR: Superior root of AC; IR: Inferior root of AC; C2, C3: ventral rami of second and third cervical nerve; SA: Scalenus anterior; OS: Superior belly of omohyoid muscle.

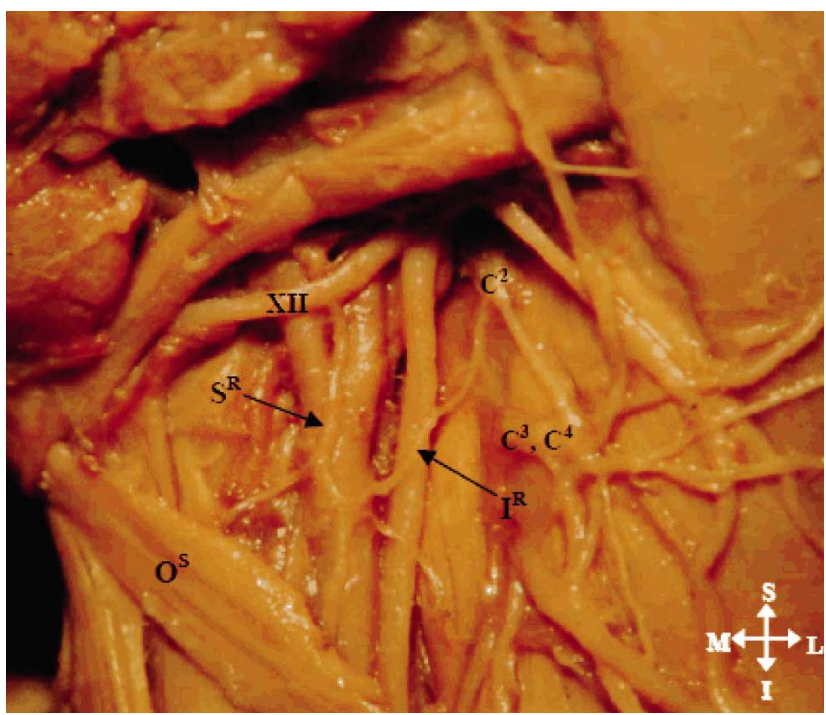

Fig. 5. Right anterior view of origin of inferior root from ventral rami of second cervical nerves.

Key= XII: Hypoglossal nerve; SR: Superior root of ansa cervicalis; IR: Inferior root of ansa cervicalis; $\mathrm{C} 2$ : ventral rami of second cervical nerve; C3, C4: ventral rami of third and fourth cervical nerves; OS: Superior belly of omohyoid muscle. 


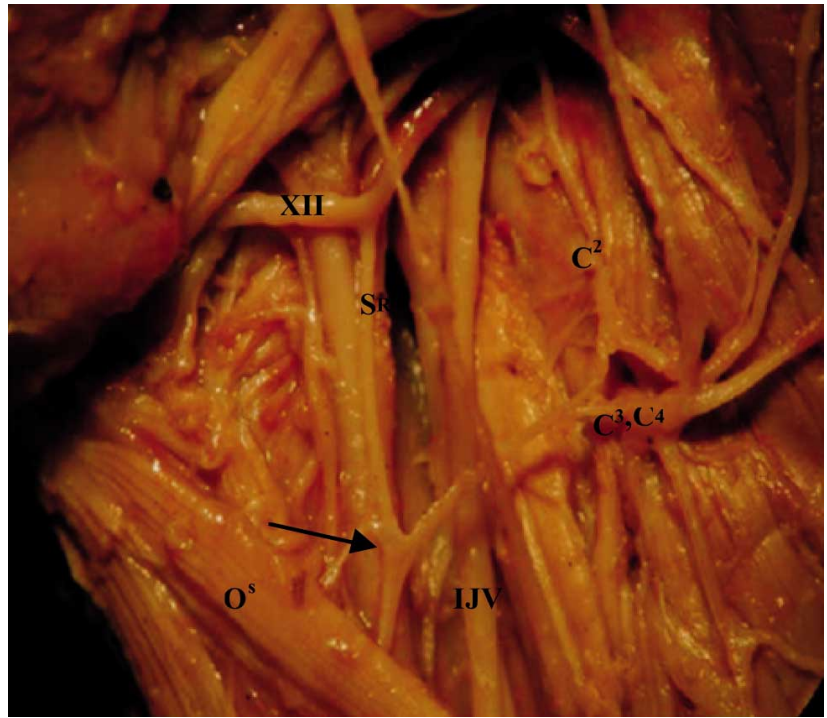

Fig. 6. Left anterior view of short $\mathrm{AC}$ and muscular branches from the loop of AC.

Key= XII: Hypoglossal nerve; SR: Superior root of AC; IR: Inferior root of AC; OS: Superior belly of omohyoid muscle; EJV: External Jugular vein.

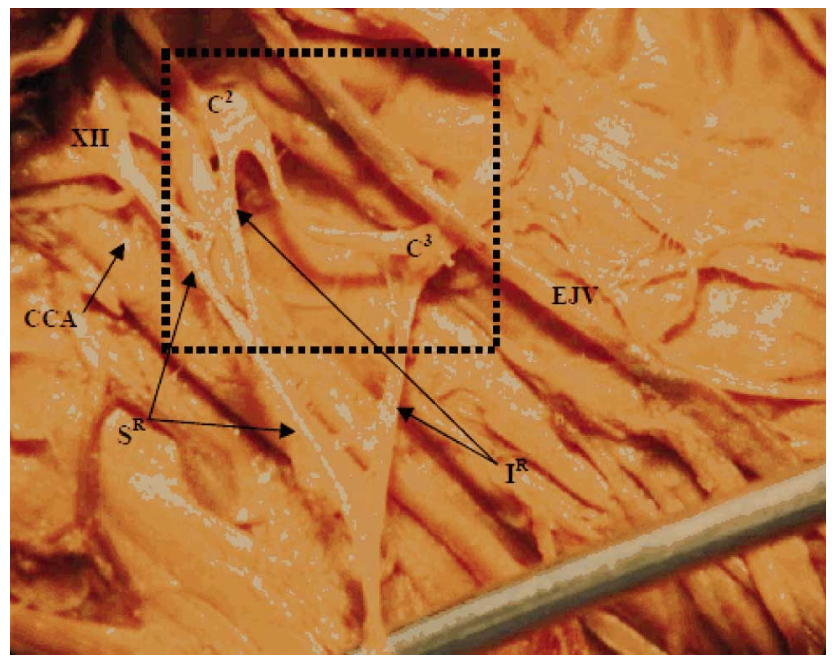

Fig. 7. Double classic form of AC with two separate roots.

Key= XII: Hypoglossal nerve; SR: Superior root of ansa cervicalis; IR: Inferior root of ansa cervicalis; EJV: External Jugular vein; C2: ventral rami of second cervical nerve; $\mathrm{C} 3$ : ventral rami of third cervical nerve.

a loop around the IJV to ascend to the ventral ramus of $\mathrm{C} 2$ as the inferior root (1/80 (1\%)) (Fig. 8- indicated by dotted square)

In $1 / 80(1 \%)$ of the fetal specimens, the AC formed a "W" shaped appearance above the superior belly of omohyoid (Fig. 9 - indicated by arrow) This was formed by

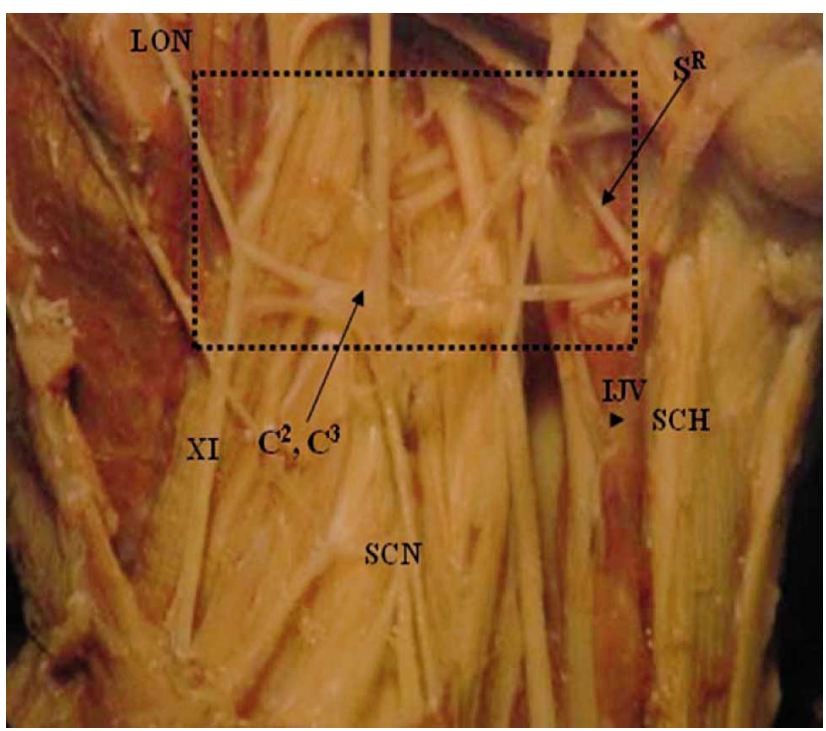

Fig. 8. Right anterior view of unusual loop of AC.

Key= XII: Hypoglossal nerve; SR: Superior root of ansa cervicalis; SCH: Sympathetic chain; IJV: Internal Jugular vein; C2, C3: ventral rami of second and third cervical nerves; SCN: Supraclavicular nerve; LON: Lesser occipital nerve.

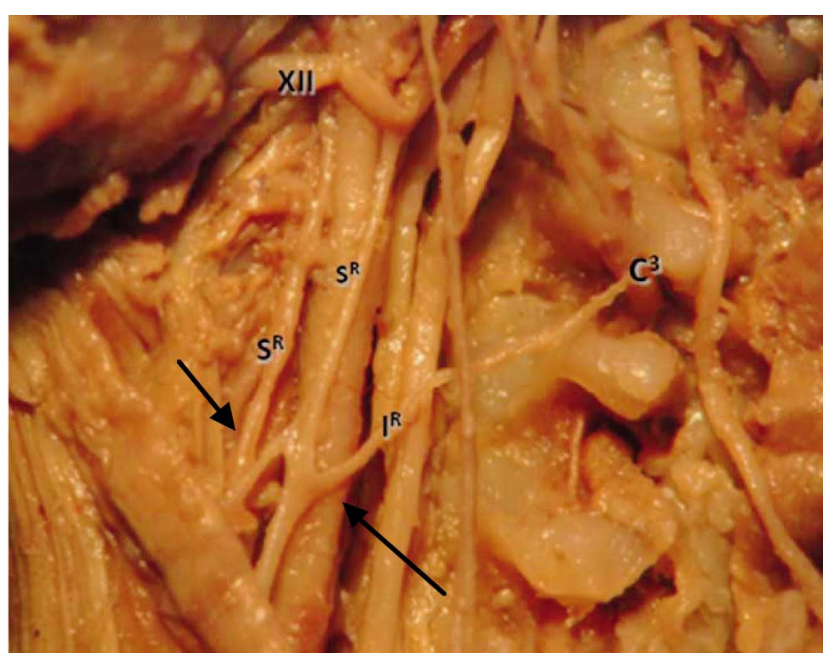

Fig. 9. Left anterior view of dual contribution from hypoglossal nerve ("W" shaped appearance).

Key= XII: Hypoglossal nerve; SR: Superior root of ansa cervicalis; IR: Inferior root of ansa cervicalis; $\mathrm{C} 3$ : ventral rami of the third cervical nerve; C1, 2, 3 and 4: First, second, third and fourth cervical vertebrae; EJV: External jugular vein; Os: Superior belly of omohyoid muscle.

a dual contribution from the hypoglossal nerve that was located parallel to each other on the common carotid artery. The inferior root was formed by the ventral ramus of $\mathrm{C} 3$. 


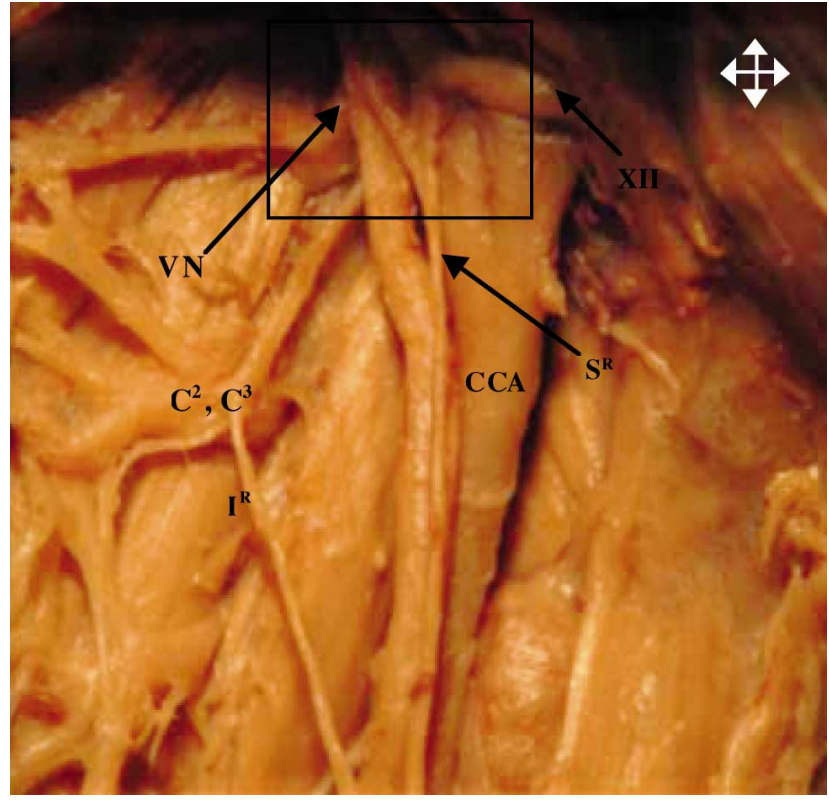

Fig. 10. Left anterior view of the "vago-cervical complex.

Key= VN: Vagus nerve; XII: Hypoglossal nerve; SR: Superior root of ansa cervicalis; IR: Inferior root of ansa cervicalis; CCA: Common carotid artery; $\mathrm{C} 2, \mathrm{C} 3$ : Ventral rami of the second and third cervical nerves.

Vago-hypoglossal-ansa cervicalis communication: In $2 / 80(3 \%)$ specimens, the superior root of AC was formed by two branches, one from the vagus nerve and one from hypoglossal, which joined anterior to the bifurcation of the common carotid artery (Fig. 10 - indicated by square). The inferior root was formed by the ventral rami of $\mathrm{C} 2$ and $\mathrm{C} 3$.

\section{DISCUSSION}

The $\mathrm{AC}$ was formed by superior and inferior roots, located in close proximity to the larynx, common carotid artery and IJV. Due to its proximity to the larynx this nerve is usually used for nerve-nerve transfer to the recurrent laryngeal during laryngeal re-innervation surgery. In the research conducted the hypoglossal nerve was observed to lie superior to the bifurcation of the common carotid artery. The superior root of AC was recognized as a willowy nerve that branched from the hypoglossal nerve. Thereafter, it descended on the carotid sheath, predominantly anterior to the IJV $(70 \%(56 / 80))$ in support of Calliot \& Dumont who recorded the descent of the superior root anterior to the carotid sheath and IJV in majority of their dissections. However, Standring \& Henry described the descent predominantly lateral to IJV.
The importance of understanding the location of $\mathrm{AC}$ to the IJV and carotid artery is to prevent inadvertent injury to these vessels during surgical procedures such as dysphonia and unilateral vocal cord paralysis. The description in standard anatomical texts of the formation of the inferior root suggests it is derived from the junction between the ventral rami of C2 and C3 (Standring \& Henry); however in this study the most frequent contributor was only from the ventral rami of $\mathrm{C} 3(58 \%)$. The superior and inferior roots join to form a loop, located either superior or inferior to the superior belly of omohyoid muscle, and this is classified as a long or short AC. In the present series utilizing Chhetri \& Berke's definition, majority of AC dissected was of the short AC classification (63/80, 79\%). Interestingly, in our study the variations of the dual ansa cervicalis formation, its unusual course and the "W" shaped appearance are unique findings. Awareness and knowledge of these variations may assist in preventing inadvertent injury to these nerves during surgical procedures.

\section{CONCLUSION}

Due to the shortage of adult cadaveric material, in this study, clarification was sought on the gross anatomy of $\mathrm{AC}$ in fetuses. Even though the gross anatomy conformed to standard anatomical textbooks, variations were encountered in the course, formation and relations to vascular structures. The precise understanding of the anatomy of AC together with variations may assist anesthetists and surgeons to accurately identify the vascular and neural relations thereby reducing the risks of complications when performing neural blocks in regional anesthesia, facial rejuvenation surgery and nerve grafts in children and young adults.

PILLAY, P.; PARTAB, P.; LAZARUS, L. \& SATYAPAL, K. S. El asa cervical en fetos. Int. J. Morphol., 30(4):1321-1326, 2012.

RESUMEN: La formación del asa cervical (AC) compleja, tanto en su curso como en ubicación, pueden variar a lo largo de la arteria carótida común y de la vena yugular interna (VYI). El objetivo del estudio fue determinar la anatomía, formación y variaciones del AC en fetos humanos. Cuarenta fetos (edad gestacional: 15 a 28 semanas) fueron obtenidos desde el Departamento de Anatomía Clínica, Westville Campus, UKZN. En cada muestra se realizó una detallada microdisección del triángulo posterior del cuello y del AC utilizando instrumental de microdisección estándar. Fueron registrados los resultados de la formación del AC, su relación con VYI y sus variaciones. La raíz superior fue identificada como un nervio largo y delgado que se ramificaba desde el nervio hipogloso, descendía por la vaina carotídea, anterior a la a. carótida común y la VYI en el 70\% de los casos, y posterior a la 
VYI el 30\%. La raíz inferior del AC se originaba desde los ramos ventrales de $\mathrm{C} 2-\mathrm{C} 3$ en el $26 \%$ de los casos; desde el ramo ventral de $\mathrm{C} 3$ en el $58 \%$ y desde el ramo ventral de $\mathrm{C} 2$ en $16 \%$ de los casos. Se observaron variaciones de formación: (i) dual del AC: el nervio hipogloso formó asas separadas con los ramos ventrales de C2 y C3 (3\%), (ii) forma aparente de "W" sobre el vientre superior del m. omohioideo (1\%) y (iii) un "complejo vago-cervical" (3\%), y variaciones de origen y curso: la raíz superior del AC recibió una contribución del nervio hipogloso, y a corta distancia formó un bucle alrededor de la VYI para ascender al ramo ventral de C2 como una raíz inferior. El conocimiento preciso de la anatomía del $\mathrm{AC}$ junto con variaciones pueden ayudar a identificar con precisión las relaciones vasculares y neuronales durante los procedimientos quirúrgicos a anestesistas y cirujanos.

PALABRAS CLAVE: Asa cervical; Raíz Superior, Raíz inferior; Nervio hipogloso, Vena yugular interna.

\section{REFERENCES}

Banneheka, S. Morphological study of the ansa cervicalis and the phrenic nerve. Anat. Sci. Int., 83(1):31-44, 2008.

Caliot, P. \& Dumont, D. A contribution to the morphological study of the ansa cervicalis. Rev. Laryngol. Otol. Rhinol. (Bord.), 104:441-4, 1983.

Chhetri, D. K. \& Berke, G. S. Ansa Cervicalis Nerve: Review of the Topographic Anatomy and Morphology. Laryngoscope, 107(10):1366-72, 1997.

Ellis, H. \& Fieldman, S. Anatomy for Anaesthetists Blackwell science publishers. Anatomy for anesthetists. $6^{\text {th }}$ ed. Oxford, Blackwell Scientic; 1993.

Kikuchi, T. A contribution to the morphology of the ansa cervicalis and the phrenic nerve. Acta Anat. Nipon, 45(5):242-81, 1970.

Kuniak, B. \& Klacansky, J. A contribution to topographic anatomy of ansa cervicalis with reference to reinnervation of the larynx. Cesk. Otolarynogol., 31(3):170-5, 1982.

Loukas, M.; Thorsell, A.; Tubbs, R. S.; Kapos, T.; Louis, Jr. R. G.; Vulis, M.; Hage, R. \& Jordan, R. The ansa cervicalis revisited. Folia Morphol. (Warsz.), 66(2):120-5, 2007.

Olry, R. \& Haines, D. E. Ansa hypoglossi or Ansa cervicalis? That is the question. J. Hist. Neurosci., 11(3):302-4, 2002.

Poviraev, N. P. \& Chernikov, Y. F. Anatomy of the ansa cervicalis. Exerpta Medica, 21(1):219, 1967.

Standring, S. \& Henry, G. Neck In: Gray's anatomy. Standring, S. (Ed.). $40^{\text {th }}$ Ed. Edinburgh, Churchill Livingstone, 2008. pp.43536.
Vollala, V. R.; Bhat, S. M.; Nayak, S.; Raghunathan, D.; Samuel, V. P. ; Rodrigues, V.; Mathew, J. G. A rare origin of upper root of ansa cervicalis from vagus nerve: A case report. Neuroanatomy, 4:8-9, 2005.

Yamada, M. \& Mannen, H. Anatomy for Dissectors. Tokyo, Nankodo, 1985. p.188.

\section{Correspondence to:}

Professor KS Satyapal

Department of Clinical Anatomy

School of Medical Sciences

Faculty of Health Sciences

Westville Campus

College of Health Sciences

University of KwaZulu-Natal

Private Bag X54001

Durban, 4001

SOUTH AFRICA

Telephone: + 27312607195

Fax: + 27312607890

Email: satyapalk@ukzn.ac.za

Received: 30-08-2011

Accepted: 22-05-2012 